\title{
Assessing needs for psychiatric treatment in prisoners: 3. Comparison of care received by black and minority ethnic prisoners and by white prisoners
}

Dr Nigel McKenzie, Associate staff member, Division of Psychiatry, University College London, Maple House, 149 Tottenham Court Road, London W1T 7NF, UK.

Professor Helen Killaspy*, Division of Psychiatry, University College London, Maple House, 149 Tottenham Court Road, London W1T 7NF, UK.

h.killaspy@ucl.ac.uk

Tel 02076799710

Dr Sharon Jakobowitz, Division of Psychiatry, University College London, Maple House, 149 Tottenham Court Road, London W1T 7NF, UK.

Hamidi Faranak, School of Population Health \& Environmental Sciences, Faculty of Life Sciences and Medicine, King's College London, Guy's Campus, London SE1 1UL, UK.

Professor Paul Bebbington, Division of Psychiatry, University College London, Maple House, 149 Tottenham Court Road, London W1T 7NF, UK.

${ }^{*}$ Corresponding author 


\section{Abstract}

\section{Purpose}

To investigate to what extent mental health treatment needs are met in white and BME (black and minority ethnic) prisoners.

\section{Methods}

Treatment needs of a random sample of male $(n=197)$ and female $(n=171)$ prisoners were assessed with standardised instruments. Interventions provided were confirmed through face-to-face interviews and case note review.

\section{Results}

BME prisoners comprised $44 \%$ of participants. Treatment for depression, personality disorder and alcohol abuse was more often needed by White than BME prisoners. Needs were more frequently met in White than BME prisoners (48.5\% vs $38.2 \%$; $p<0.05)$, largely due to delivery of psychological treatments.

\section{Conclusions}

BME prisoners had fewer of their mental health needs met.

\section{Keywords}

Mental disorder, Prisoners, Treatment needs, Ethnic differences

\section{Word count 1348}




\section{Introduction}

Over twenty years ago the British National Survey of Psychiatric Morbidity among Prisoners (1997) [1] documented extremely high rates of psychiatric disorder and poor availability of psychiatric treatment in prisoners. Prisoners often asked for help with their problems, but such requests were rejected twice as often in prison as in the period immediately beforehand, indicating that prison-based mental health services were performing poorly. Provisions for rectifying this were established in the late 1990s, based on the principle of equity: prisoners should receive the same level of mental health care in prisons as they would in the community. To facilitate this, the National Health Service took over responsibility for prison health care services in 2006.

Following these changes, we carried out a psychiatric survey in a representative sample of prisoners in a male and a female prison in London (Pentonville and Holloway), and confirmed persistently high rates of psychiatric disorder and comorbidity; $70 \%$ of prisoners had two or more disorders and $11.7 \%$ had at least five [2]. We also made a structured assessment of their mental health treatment needs, and of the extent to which they had been met. While over $80 \%$ of female and $70 \%$ of male prisoners were identified as needing treatment for a psychiatric condition, around half these needs were unmet [3]. Equity requires that prisoners should have equal access to care regardless of their ethnicity [4]. Identifying, understanding, and reducing disparities in care is of great importance in developing equitable mental health services. Evidence from general population surveys shows people from black and minority ethnic (BME) groups are disadvantaged relative to their white peers in accessing mental health care, and this has driven service changes $[5,6]$. However it is not clear whether these ethnic disparities in care are also seen in prisoners $[7,8,9]$. We here present our findings for treatment needs and how far these needs are met for black and minority ethnic prisoners compared to white prisoners.

\section{Method}

Male remand, female remand, male sentenced, and female sentenced prisoners were randomly sampled in equal numbers. The sequential sampling procedure and its rationale are detailed elsewhere [2], along with the seven instruments for identifying psychiatric disorder. Only one included a screening component (to identify possible psychosis). The 
methods used to assess how effectively the prison psychiatric services identified and met the needs for treatment of prisoners with psychiatric disorders, and to what extent prisoners were willing to accept such treatment are described in a second paper [3]. Treatments were considered in detail, and included pharmacotherapy and a range of psychological treatments. The Needs for Care Assessment was used to identify needs for the treatment of operationally defined significant clinical problems. It requires information about mental state and the course of disorder, as well as social functioning, social stresses, the treatments received, and the service users' attitudes towards them [10]. These requirements were met by a range of instruments [11-13]. The assessment includes the judgement of a panel of clinicians (including PB and NM) as to whether an identified need is met, unmet or unmeetable. The latter applies if appropriate treatment does not exist (distinct from there being inadequate resources to provide it) or if the individual declines treatment. The final sample comprised 368 participants (197 males, 171 females), of whom 360 completed the Needs for Care Assessment interview.

We had aimed to compare the pathways to care and the care received for people with identified treatment needs (at the individual and overall need levels) from different ethnic groups six and 12 months after their initial mental health needs assessment. This proved difficult. Although 104 male and 45 female prisoners were willing to be followed up, three months after consenting only 57 male and 18 female prisoners were either still in prison or otherwise contactable. Information was gathered in a single follow-up interview about the mental health interventions they had received, and corroborated with data from the prison's electronic record systems.

\section{Results}

\section{Demographic and clinical characteristics of prisoners}

Of the initial participants, $44 \%$ were from a BME group (males: $46.7 \%$ White British, $33.0 \%$ Black, 5.6\% Asian, 14.7\% other BME group; females: 66.1\% White British, 15.2\% Black, 2.9\% Asian, $15.8 \%$ other BME group). BME prisoners were more likely to have achieved standard school leaver (General Certificate of Secondary Education) or higher educational qualifications than White prisoners $\left(63.2 \%\right.$ vs $\left.46.3 \% ; X^{2}=9.7, p=0.002\right)$, and to have been in work in the 12 months prior to coming into prison (55.2\% vs $\left.37.6 \% ; X^{2}=10.7, p=0.001\right)$. Compared to their White British counterparts, BME prisoners were less likely to have had 
contact with mental health services before their current sentence $\left(19.6 \%\right.$ vs. $29.8 \% ; X^{2}=4.4$ $p=0.04)$.

Both prisoner groups had high rates of disorder. Of BME prisoners, slightly more $(23 / 163$, $14.1 \%)$ met criteria for psychosis than White prisoners $(22 / 205,10.7 \%)$, a statistically nonsignificant difference. In contrast, fewer BME prisoners than White prisoners met the criteria for phobia (3.7\% vs. $16.6 \%)$, panic disorder (2.5\% vs. $7.8 \%)$, PTSD (3.7\% vs. $11.4 \%)$ and alcohol dependence (23.9\% vs. $40.0 \%)$. These differences were statistically significant. Similar percentages of BME and White prisoners met criteria for depressive episode $(22.7 \%$ vs. $22.0 \%)$, anxiety state ( $21.7 \%$ vs. $30.9 \%)$, personality disorder (31.9\% vs. $36.1 \%)$ and drug dependency (59.6\% vs. 55.1\%).

\section{Needs for Care}

The extent of significant clinical problems identified in the Needs for Care Assessment are shown in Table 1. Similar percentages of BME and White prisoners had problems identified relating to psychosis, but BME prisoners were significantly less likely than White prisoners to have problems identified that were associated with depression, personality disorder or alcohol abuse at initial assessment.

Table 1 also presents the results of whether prisoners' needs for treatment were met, unmet or unmeetable. Although the Needs for Care Assessment identified a higher percentage of White prisoners as having treatment needs for depression, personality disorder and alcohol abuse than BME prisoners, there were no statistically significant differences between the two groups in whether these needs were met. However, in all categories, needs were more frequently met in White prisoners. Thus when all disorders were combined, the overall level of met need was statistically higher for White compared to BME prisoners (48.5\% vs $38.2 \% ; p<0.05$ ). When needs were divided according to the type of treatment required, needs for medication were more frequently met in BME prisoners though the difference was non-significant. However, needs for psychological treatments were met significantly more often in White prisoners, after excluding treatments for alcohol or drug abuse (44.2\% vs $26.5 \% ; p<0.05)$. 
The 59 prisoners who were followed-up three months after the Assessing Needs study for

\section{Discussion and conclusions}

We found non-significantly higher levels of psychosis in BME prisoners than their White counterparts. However common mental disorders were less frequent. This tallies with similar results in community based studies $[14,15]$.

Our main finding is that BME prisoners had significantly fewer of their mental health needs met at the point of initial assessment. Given our problems of follow-up, little weight can be placed on the apparent narrowing of this gap three months later. The fact that those followed up had similar needs to the whole sample suggests this was not because they had more severe problems (which were therefore more likely to be noticed and addressed) than those who had left prison and could not be followed-up.

BME prisoners had higher levels of education and were more likely to have been in work in the year before coming into prison, attributes that might be expected to augment access to care, contrary to our results. This unexpected finding might have arisen from higher levels of white-collar crime among the sampled BME prisoners but we did not have access to the details of participants' index offences that would allow us to explore this theory. However, it could equally arise from a lower general threshold for imprisoning members of BME groups, whereby the influence of other types of social disadvantage would be attenuated.

The reasons for greater unmet need in BME prisoners are unclear. Language difficulties in some cases might make it harder to identify mental illness. Cultural factors may inhibit some groups from seeking help for mental health issues. Perceived barriers between the majority culture and that of particular ethnic groups could be a contributing factor. These factors may also explain why BME prisoners more often received medication rather than psychological 
treatments compared to the White counterparts. The induction process for admitting someone to prison, as set out in Prison Service Order 0550, does take account of the cultural and language barriers that BME prisoners may experience. However, staff should receive regular training on how to recognise possible mental health issues in BME prisoners, and how best to achieve close collaboration with prison mental health in-reach teams so that their needs are met.

\section{Conflict of interest statement}

On behalf of all authors, the corresponding author states that there is no conflict of interest.

\section{Acknowledgements}

This study was funded by the National Forensic Mental Health R\&D Programme (Ref. MRD $12 / 83)$.

\section{Compliance with ethical standards}

Ethical approval was obtained from the Thames Valley Research Ethics Committee (Ref. 05/MRE 12/52), in line with the 1964 Declaration of Helsinki and its later amendments. 
Table 1 Overall need status for treatment of different disorders

\begin{tabular}{|c|c|c|c|c|c|c|}
\hline \multirow[t]{2}{*}{ Need status } & \multicolumn{2}{|c|}{$\begin{array}{l}\text { White } \\
\mathrm{N}=205\end{array}$} & \multicolumn{2}{|c|}{$\begin{array}{c}\mathrm{BME} \\
\mathrm{N}=155\end{array}$} & \multicolumn{2}{|c|}{$\begin{array}{l}\text { TOTAL } \\
\mathrm{N}=360\end{array}$} \\
\hline & $\mathbf{N}$ & $\%$ & $\mathbf{N}$ & $\%$ & $\mathbf{N}$ & $\%$ \\
\hline Psychosis total & 17 & 8.3 & 13 & 8.3 & 30 & 8.3 \\
\hline Met & 9 & 52.9 & 6 & 46.2 & 15 & 50.0 \\
\hline Unmet & 7 & 41.2 & 5 & 38.5 & 12 & 40.0 \\
\hline Unmeetable & 1 & 5.9 & 2 & 15.4 & 3 & 10.0 \\
\hline Depression total** & 77 & 37.6 & 36 & 23.2 & 113 & 31.4 \\
\hline Met & 30 & 39.0 & 12 & 33.3 & 42 & 37.2 \\
\hline Unmet & 46 & 59.7 & 19 & 52.8 & 65 & 57.5 \\
\hline Unmeetable & 1 & 1.3 & 5 & 13.9 & 6 & 5.3 \\
\hline Anxiety total & 5 & 2.4 & 6 & 3.9 & 11 & 3.1 \\
\hline Met & 2 & 40.0 & 1 & 16.7 & 3 & 27.3 \\
\hline Unmet & 3 & 60.0 & 4 & 66.7 & 7 & 63.6 \\
\hline Unmeetable & 0 & 0.0 & 1 & 16.7 & 1 & 9.1 \\
\hline Adjustment Disorder total & 5 & 3.0 & 7 & 4.5 & 12 & 3.3 \\
\hline Met & 1 & 20.0 & 1 & 14.3 & 2 & 16.7 \\
\hline Unmet & 4 & 80.0 & 5 & 71.4 & 9 & 75.0 \\
\hline Unmeetable & 0 & 0.0 & 1 & 14.3 & 1 & 8.3 \\
\hline PTSD total & 14 & 6.8 & 5 & 3.2 & 19 & 5.3 \\
\hline Met & 2 & 14.3 & 0 & 0.0 & 2 & 10.5 \\
\hline Unmet & 12 & 85.7 & 5 & 100.0 & 17 & 89.5 \\
\hline Unmeetable & 0 & 0.0 & 0 & 0.0 & 0 & 0.0 \\
\hline Personality Disorder total* & 25 & 12.2 & 10 & 6.5 & 35 & 9.7 \\
\hline Met & 8 & 32.0 & 3 & 30.0 & 11 & 31.4 \\
\hline Unmet & 16 & 64.0 & 6 & 60.0 & 22 & 62.9 \\
\hline Unmeetable & 1 & 4.0 & 1 & 10.0 & 2 & 5.7 \\
\hline Alcohol abuse total** & 81 & 39.5 & 42 & 27.1 & 123 & 34.2 \\
\hline Met & 42 & 51.9 & 16 & 38.1 & 58 & 47.2 \\
\hline Unmet & 27 & 33.3 & 20 & 47.6 & 47 & 38.2 \\
\hline Unmeetable & 12 & 14.8 & 6 & 14.3 & 18 & 14.6 \\
\hline Substance abuse total & 81 & 39.5 & 59 & 38.1 & 140 & 38.9 \\
\hline Met & 54 & 66.7 & 29 & 49.2 & 83 & 59.3 \\
\hline Unmet & 19 & 23.5 & 21 & 35.6 & 40 & 28.6 \\
\hline Unmeetable & 8 & 9.9 & 9 & 15.3 & 17 & 12.1 \\
\hline \multicolumn{7}{|c|}{$\begin{array}{l}\text { Success in meeting specific treatment needs } \\
\text { identified at initial recruitment }\end{array}$} \\
\hline All treatments & 305 & & 178 & & 483 & \\
\hline Met ${ }^{*}$ & 148 & 48.5 & 68 & 38.2 & 216 & 44.7 \\
\hline Unmet & 134 & 43.9 & 85 & 47.8 & 219 & 45.3 \\
\hline Unmeetable & 23 & 7.5 & 25 & 14.0 & 48 & 9.9 \\
\hline Medication & 62 & & 40 & & 102 & \\
\hline Met & 35 & 56.5 & 25 & 62.5 & 60 & 58.8 \\
\hline Unmet & 23 & 37.1 & 10 & 25.0 & 33 & 32.4 \\
\hline
\end{tabular}




\begin{tabular}{|l|r|r|r|r|r|r|}
\hline Unmeetable & 4 & 6.5 & 5 & 12.5 & 9 & 8.8 \\
\hline Psychological & $\mathbf{2 2 1}$ & & $\mathbf{9 3}$ & & $\mathbf{3 1 4}$ & \\
\hline Met & 115 & 52.0 & 39 & 41.9 & 154 & 49.0 \\
\hline Unmet & 82 & 37.1 & 36 & 38.7 & 118 & 37.6 \\
\hline Unmeetable & 24 & 10.9 & 18 & 19.4 & 42 & 13.4 \\
\hline
\end{tabular}

White Br vs BME: * $p<0.05 ;{ }^{* *} p<0.01$ 


\section{References}

1. Singleton N, Meltzer H, Gatward R, Coid J, Deasy D (1998) Psychiatric morbidity among prisoners in England and Wales. TSO, London.

2. Bebbington P, Jakobowitz S, McKenzie N, Killaspy H, Iveson R, Duffield G, Kerr M (2016) Assessing needs for psychiatric treatment in prisoners: 1 . Prevalence of disorder. Soc Psychiatry Psychiatr Epidemiol 52:221-229

3. Jakobowitz S, Bebbington P, McKenzie N, Iveson R, Duffield G, Kerr M, Killaspy H (2017) Assessing needs for psychiatric treatment in prisoners: 2. Met and unmet need. Soc Psychiatry Psychiatr Epidemiol 52:231-240

4. Department of Health (2005) Delivering Race Equality in Mental Health Care. TSO (The Stationery Office)

5. Bhui K, Stansfeld S, Hull S, Priebe S, Mole F, Feder G (2003) Ethnic variations in pathways to and use of specialist mental health services in the UK Systematic review Br J Psychiatry 182:105 -116

6. Sass B, Moffat J, Bhui K, Mckenzie K (2009) Enhancing pathways to care for black and minority ethnic populations: A systematic review. Int Rev Psychiatry 21:430-438

7. Coid J, Petruckevitch A, Bebbington P, Brugha D, Jenkins R, Farrell M, Lewis G, Singleton N (2002) Ethnic differences in prisoners: II. risk factors and psychiatric service use. Br J Psychiatry 181:481-487

8. Bhui, K, Brown P, Hardie T, Watson JP, Parrott J. (1998) African-Caribbean men remanded to Brixton Prison. Psychiatric and forensic characteristics and outcome of final court appearance. $\mathrm{Br} J$ Psychiatry 172:337-344

9. Denzel AD, van Esch AYM, Harte JM, Scherder, EJA (2016) Ethnic variations in psychotic disorders in the criminal justice system: A systematic review. Aggression and Violent Behavior 29:20-29

10. Bebbington PE, Marsden L, Brewin C, Lesage A (1996) Measuring the need for psychiatric treatment in the general population: the community version of the MRC needs for care assessment. Psychol Med 26:229-236

11. Lewis G, Pelosi A, Araya RC, Dunn G (1992) Measuring psychiatric disorder in the community: a standardized assessment for use by lay interviewers. Psychol Med 22:465-486

12. Brown GW, Harris TO (1978) Social origins of depression: a study of psychiatric disorder in women. Tavistock, London

13. (WHO 1992). World Health Organization (1992) SCAN: schedules for clinical assessment in neuropsychiatry. WHO, Geneva

14. King M, Nazroo J, Weich S, McKenzie K, Bhui K, Karlsen S, Stansfeld S, Tyrer P, Blanchard M, Lloyd K, McManus S, Sproston K, Erenns B (2005) Psychotic symptoms in the general population of England A comparison of ethnic groups (The EMPIRIC study). Soc Psychiatry Psychiatr Epidemiol 40:375-381

15. Weich S, Nazroo J, Sproston K, McManus S, Blanchard M, Erens B, Karlsen S, King M, Lloyd K, Stansfeld S, Tyrer P Common mental disorders and ethnicity in England: the EMPIRIC Study (2004) Psychol Med 34:1543-1551 